\title{
Boosting maternal health care seeking behavior in rural low income communities: A case study of West Gojam and South Wollo Zones in Amhara, Ethiopia
}

\author{
Hailom Banteyerga \\ Addis Ababa University, College of Humanities, Language Studies, Journalism and Communication, Addis Ababa, Ethiopia
}

\section{Email address:}

hailombante@yahoo.com

\section{To cite this article:}

Hailom Banteyerga. Boosting Maternal Health Care Seeking Behavior in Rural Low Income Communities: A Case Study of West Gojam and South Wollo Zones in Amhara, Ethiopia. American Journal of Health Research. Vol. 2, No. 6, 2014, pp. 378-386.

doi: 10.11648/j.ajhr.20140206.20

\begin{abstract}
Taking the national scenario in maternal health care, it was taken for granted that Ethiopia would not meet the millennium development goal in the reduction of maternal death: assisted birth at a health institution for example was as low as $10 \%$ in 2011. Although, the introduction of the health extension program since has enabled the health sector to make major strides towards health promotion and disease prevention, health facility utilization in maternal health care remained low. An ecologically driven health development army (HAD) of thirty members sub structured into community cell based networking of 1-5 has been introduced to guide social mobilization and community participation in health as of 2012 . The networking requires all women and men to be teamed in 1-5 cells, actively participate in learning and practicing good health. The analysis of the effect of the networking on boosting maternal health care seeking behavior in rural communities was made using qualitative data obtained from informant interviews and focus group discussions in Amhara, West Gojam and South Wolo Zones. The data analysis looked into inputs, processes, outcomes/outputs, effects and impacts of the networking in maternal health care. The analysis showed that the networking of communities in HAD of 1-30 and substructures of 1-5 is transformative in boosting health care seeking behavior. Study participants demonstrated, irrespective of age, religion and gender, shared health information and attitude towards pregnancy, birth, and the need to mitigate health risks by attending care and treatment services at health facilities. All stakeholders at community and leadership position give credit to the social network of HDA for enhancing maternal care seeking behavior in beneficiaries and responsiveness of heath providers in health facilities to meet health care needs of mothers. The impact of the networking is that communities are empowered and are assuming ownership with regards to dealing with their health care needs. In effect they are demanding for availability of quality of maternal health care services at closer locations. The lesson learnt is that through the use of innovative methodologies and approaches, communities can assume leadership in producing good health. In such a scenario, it is suggested that governments should mobilize resources, local and as well international to improve the supply side of maternal and child health care services. Failure to meet what communities are demanding in health care service delivery would result in dissatisfaction and lack of trust in the health system.
\end{abstract}

Keywords: Maternal Care, Health Development Arm Networks, Promotion of Health Care Seeking Behavior, Health Service Delivery, MDGs

\section{Introduction}

The government of Ethiopia formulated a health policy in 1993 [17]; and a twenty year Health Sector Development Program in 1997 [8] deliverable in four phases, each lasting five years. In order to improve on access to health services, the health system has been decentralized and it now operates in three tiers. A primary hospital, health center and health posts form a primary health care unit (PHCU) with each health center having five satellite health posts. The second level in the tier is a General Hospital with population coverage of 1-1.5 million people; and the third a Specialized Hospital that covers population of 3.5-5 million. [10].

It is, however, reported that maternal health care services utilization is low in Ethiopia and many mothers untimely die or get disabled as a result. It is estimated that there are on the average yearly 20,000 maternal deaths, 118,000 newborn 
deaths and 500,000 maternal disabilities. [10]. Teen age pregnancy is estimated at $17 \%$, causing a lot of abortion related complications and deaths. [5]. About $80 \%$ of all maternal deaths in Ethiopia are due to hemorrhage, infection, unsafe abortion, hypertensive disorders and obstructed labor, along with HIV and AIDS and malaria. [13] The UN Population Fund (UNFPA) reported that in Ethiopia some of the hospitals are lacking in equipment, skills or policy guidance to enable them to provide basic emergency obstetric and newborn care; only $51 \%$ of hospitals could offer comprehensive care; most hospitals are ill-equipped, poorly staffed and suffer stock outs and obstetric care equipment shortages due to budget deficits and poor management. [18]. A study that looked into factors affecting utilization of skilled maternal care in northwest Ethiopia (Amhara), for example, showed that in the study population $13.8 \%$ delivered at health facility; $32.3 \%$ received antenatal and $6.3 \%$ post natal care. The study noted that community awareness and perception about skilled providers and their care, and quality of care women receive at health facilities are determinates to improve utilization of maternal health care services. [1].

With regards to low use of health facilities for delivery by mothers, there is an overwhelming blame on cultural practices as to why women choose home for birth instead of health facility. Birth is influenced by the perception that delivery is a normal practice that a woman should perform at home. Although women are appreciative of facility birth, they prefer home birth to institutional birth; they only seek skilled assistance when labor is prolonged and danger signs, such as bleeding, appear. [4]. The position assumed during delivery at home is mostly kneeling while in clinics women have to open up and stretch their legs, which they do not like to do so, for it exposes their private bodies to birth attendants. Moreover, the care women get at home after birth is supportive and warm which is accompanied by preparation of traditional foods and coffee ceremonies. Most births also happen in rural areas where maternal health care services are limited or do not exist. [5].

Cognizant of the problems described, the Federal Ministry of Health introduced several mechanisms to reduce maternal and neonatal deaths associated with pregnancy and birth. It trained health extension workers to assist in vaginal delivery. [9]. It has expanded on ambulance services to transport women in labor to health facilities without any fee chargeable, raising the number of ambulances on service from 1262 with new purchase of 450. [11]. It made maternal care services in health facilities free of charge as well. It has increased the number of hospitals and health centers. The number of universities training health providers has increased to seven and in effect a health center has at least two trained midwives, health officers and other health providers. In 2013, 1492 midwives were trained in BEmONC, enabling the allocation of two midwives in each health center. [11]

In order to raise health care seeking behavior of rural communities where maternal and child health care are emphasized, women health development armies of 1-30 teams and sub teams of 1-5 cells have been introduced as of
2012. [11]

In EFY 2005[2012], capacity building was carried out based on the healthy behavior bottleneck analysis. In particular, the training emphasizes on improving utilization of high impact maternal and newborn health services, and it is facilitated by HEWs with support from the primary health care unit (PHCU) and the woreda health office (WorHO). The HDA is designed to accomplish the following critical tasks: (i) identify locally salient bottlenecks that hinder families from utilizing key services and implementing the HEP, and prioritize those that they want to address as a team; (ii) come up with feasible strategies to address these problems; (iii) implement the strategies; and (iv) evaluate their activities.

The FMOH quotes an estimate made by WHO, UNICEF, UNFPA and the World Bank, maternal mortality ratio has declined in Ethiopia to 420/100,000 live births in 2013 from that $1400 / 100.000$ in 1990 , a $70 \%$ reduction. [12 ]. The FMOH has also committed to reduce MMR from $676 / 100,000$ live births in 2011 to $267 / 100,000$ by 2015 . The use of the HAD is designed to be instrumental in dealing with delay at home and transporting women showing signs of labor to nearby health facilities. The improvement in ambulance services and the making of maternal care including ambulance free of charge is believed to be motivating for women especially their husbands to decide to choose health facility for birth. The improved service delivery in health facilities is expected to mitigate delay in health facilities. Scaling up in family planning services in rural communities is taken as a strategy to reduce MMR, too. All these put together in practice would radically reduce MMR, enabling the country to meet MDG targets in health. [11].

The paper looks into the work of the health development army and its substructures of 1-5. It attempts to describe, evaluate and explain how the network is transforming the knowledge, attitude and practice of rural communities in seeking maternal health care. It analyzes how the network impacted provider responsiveness to maternal care needs of rural mothers, too. It is hoped that the insight obtained from the Ethiopia experiment could be of relevance to low income countries struggling to meet MDG goals in health particularly in the reduction of maternal deaths.

\section{The Research Methodology}

The study methodology is explorative and descriptive in nature. It is primarily based on qualitative data drawn from interviews and focus group discussions with different stakeholders in health in four districts in Amhara. The design looks into what the inputs, processes, outputs, effects and impacts of the network looks bring to boost maternal health care seeking behavior and provider responsiveness to maternal care needs of mothers.

(1) Input-- what the health system injects to the 1-5 cells. This looks into what the community health workers, facility health providers, health leaders and cell 
members bring to the networks. Input includes health information/messages; health related experiences, leadership and decision making capabilities.

(2) Process as a corollary input-how the network functions. It looks into 1-5 cell formation, leadership, agenda setting, discussions and decision making, problem solving;

(3) Outputs-- the outcomes of the process; access to health care services, ANC visits, facility based birth/delivery, postnatal care;

(4) Effect-- attitudinal changes towards institutional maternal care; provider assisted birth as opposed to traditionally assisted home birth.

(5) Impact-- the demand for maternal health care services by communities and their involvement to improve the supply side of health service delivery: demand for skilled assistance including normal delivery(ANC, Birth and PNC,) and management of complications; mitigating teenage pregnancy; improving facility spaces for maternity care such as waiting room, mothers' waiting home; youth friendly services in reproductive health.

The study on boosting maternal health care seeking behavior was conducted in four districts in Amhara regional state: Dembecha and Quarit in West Gojam; Leghida and Albuko in South Wollo. A similar study was made on the same topic in 2013 in Welega [14]. Since the new approach of social networking and mobilization was just introduced at the time of data collection in Welega, the author decided not to include the data for analysis. The four districts in Amhara were purposely selected by the client ${ }^{1}$ considering accessibility where one district is remotely located from the other: Quarit vs Dembecha in West Gojam; and Legihida vs Alebuko in South Wollo. One kebele from each district connected to an accessible health center was considered for community data collection [15].

Data collectors were all $\mathrm{PhD}$ students trained in interviewing techniques and facilitating group discussions. The guides for in-depth interviews and focus group discussions were adopted from the protocols developed by Family Care International - Skilled Care Initiative Qualitative Research guides [7]. The use of maternity waiting home was added, for it is a new practice to deal with home delay usually described as delay 1 , for mothers living in remote villages. Since the instruments were piloted in the Welega study [14], they were directly used with some modifications for data collection in West Gojam and South Wollo.

Study preparation started in January 2014 and field data covered the month of August, 2014. The data included 106 in-depth interviews and 14 community FGDs. An oral informed consent form was read to solicit the willingness of the individuals to participate in the study. The form included information on the purpose of the study, the time it took, the

${ }^{1}$ Collaborative project between the Federal Ministry of Health (FMOH), Amhara Regional Health Bureau (ARHB) and the Dutch Government -ORIO Program procedures to be followed, and the benefits and the possible risks - if any. The potential participant was also informed that he/she can refuse to answer any question and that he/she can quit the interview at any point.

Interviewees and FGD participants included health leaders at region, zone, district and relevant sector heads - education, women, children and youth affairs and communication offices; adolescent women age 15-24; mature married women age 25-45 with recent births; married men, women with complications; influential elderly women; influential elderly men; community leaders, religious leaders Community health workers, HEWs; health center/hospital providers.[see attached annex]

Interviews and FGDs were voice recorded, transcribed and translated to English. The open coding system for qualitative study was used to categorize themes. Thematic analysis of inputs, processes, outputs, effects and impacts was made to describe the capacity of the networked approach of 1-5 in boosting maternal health care seeking behavior of communities and responsive provider service delivery. It also looked into the long term implications to the supply side of health care services especially in maternal health care for the country with low income.

\section{Study Limitations}

The author acknowledges that the study has limitations in that it is based on qualitative data and can only claim transferability of findings. Findings cannot be generalized to any study population. This is the reason why the study does not look to respondents' behavior by categories of informants The main objective of this paper is to look to how the networking of $1-5$ cells is influencing behavior of communities and providers towards maternal health care. The qualitative data obtained, surprisingly, does not show worthwhile variations among informants, though varied by gender, age and societal roles, towards maternal health care in knowledge, attitude and practice. This could be due to the fact that all men and women are networked and intensively deal with one health package at a time.

\section{Findings}

The findings show that the 1-5 cell based network of social mobilization in health lend itself to the input-processoutput-effect-impact model of behavioral data analysis. The findings are reported accordingly.

\subsection{Inputs and Processes}

The main input is health information and messages in the health extension packages. Health extension workers train selected cell leaders on weekly basis on maternal health care for the implementation of the maternal and child health care package. They train leaders of the health development army on monthly basis. They use the 1-5 cell based structures of women and 1-30 health development armies to educate and pass health information to members of cells. Health 
extension workers supported by health facility providers also give educational input to all kebele dwellers on biweekly basis. The general kebele meeting enables participants to reflect on what they learned and challenges they faced in the process. They use the meeting to look for away forward that cells should do till the subsequent meeting. The process repeats where communities set the agenda on translating into practice all maternal care services: identifying pregnant women, counseling them to be registered in health posts, and taking laboratory tests which also involves husbands in health centers, following up all required checkups of ANCs, preparing for facility birth involving husbands during NC4, and accessing post partum care services for the mother and new born. When the process is put in motion, the input comes from cell leaders and members, for they mostly reflect their experiences in putting the package into practice. They agree on the steps to be followed to speed up the implementation of the family health package, and is true with other packages as well. If there are families that show resistance to antenatal care, institutions birth, they are identified and counseled. Midwives participate in such cases. The pregnant mothers' conferences which are conducted on monthly basis help women to ask questions and express their fear to providers including reporting about experiences of women who gave birth in health facility. The practice of kneeling position during delivery is being introduced in health facilities as a result of women's demand for it as an option. Close family members including husbands are allowed to be in the delivery room during birthing. Community based associations such as youth, women, and farmers; kebele and district leadership, and government sectors such as women, children and youth affairs, education, communication office reinforce community health workers activities in their endeavors to inculcate in communities the values and benefit of institutional maternal health care services.

Expectant of the demands the communities seek in maternal health care, the government has made some improvements in service delivery at health facilities, too. It has upgraded the capability of health extension workers to assist in vaginal birth since most villages are located far from accessible road by car. It has made ambulances service available free of payment though limited in coverage. In some cases any government car is used to transport a woman in emergency labor in case the ambulances are on duty and not available at the time of call. It has made some improvement in the management of complications by assigning two skilled midwives in each health center and making emergency services for mothers with complications open 24 hours at referral hospitals. Maternity waiting homes are being expanded to accommodate women expecting birth-women coming from distant and inaccessible villages. Rural communities are organized in cells and development armies to respond to emergency situations when needed. They transport a woman by using traditional ambulance (stretcher) to a place where an ambulance or a car could reach. They accompany pregnant women that live in remote rural areas if they decide to stay close to a health facility as advised by the health extension worker. All these are encouraging women and their family members to take pregnancy, institutional birth and post partum care seriously

The educational, communication, and care processes are all inclusive and interlinked. Unlike the diffusion model which puts change to innovation by categories of recipients, [2 and 11], the HDA networking approach works to transform all members in a cell of 1-5 to respond to innovations and technologies positively.

The decision making process though structured is participatory. Rural communities are organized in cells of 1-5 by gender as suited to their place of residence and work. The leader of a cell is selected for demonstrating better performance in translating the health packages to practice. The best performing woman is the leader of the health development army of 30 . Then, there is a command post usually chaired by a school director. The health extension workers, other development agents working in the rural sites are members of the command post. At district level the command post is chaired by the district administrator; the representative of women, children and youth is the vice chair. Education, health, law enforcing sectors such as police, justice, and government communication office are members. Any obstacle to implementing a package is dealt at cell level. If problems related to underage marriage, rape and coerced sex are reported they are dealt at command post level.

The decision making process is participatory. The vertical reporting, however, is fast. The cell community structure is a key tool in the decentralization process where districts are authorized to make decisions on setting and implementing development agenda. Main development targets are based on MDGs.

\subsection{Outputs/Outcomes}

The process of networked behavior change education/communication as reflected by all respondents and FGDs show the following outcomes/outputs of communication behavior. (i) Health and other development packages assume centrality in community discourse. As members of families are also organized in cells, the discussion in cells resonates in household discussions. The discussions of cell leaders bring to each cell what other experiences have been observed in other cells and why some cells have performed better in implementing an activity say identifying and registering pregnant women, ensuring ANC follow up, preparing for birth at health facility, saving money to cover expenses required in case of emergencies. (ii)The performance of communities and households, cells is assessed and described as High, Middle, and Low on the basis of a checklist prepared to evaluate community performance of a health package implemented. This process has created competition among cells, health development armies, clustered sub villages, villages and even districts. Households that are less cooperative are counseled and given more education till they show cooperation for change. Zero home birth is one of the main criteria considered in determining the 
performance of a cell and or team of health development army, for example. The process is open to competition including taking leadership position in cells and development armies and as well as positions in command posts. It requires cells, leaders, sub villages, villages and districts to be innovative in implementing activities for the realization of pre set goals such as zero home birth. Health officers at region and zone levels monitor progress and outcomes based on use of maternal health care services. They plan and organize capacity building activities of health facilities, community health leaders and workers. The process fosters commitment, openness, accountability, interactivity proactive leadership in dealing with challenges. It takes development be it in health or otherwise from the top to the community. It promotes competition through team cooperation--the cell based networking of social mobilization for behavior change in health gives more support to bring members to the same level of understanding in maternal health care through individual counseling and family discussions.

(iv) The HAD approach to health promotion is ecological and context driven. The life style in rural communities is governed by social cooperation, discussion, consultation and that is why the approach is more of ecological rather than top down. So the grouping approximates behaviors of families and neighbors. It reflects the way of life of rural people and is conducive for passing and understanding new messages, be it health or other rural development technologies. The conversations that take place among peers be it women or men are democratic and facilitate development of social cognitive skills and abilities of members. The FGDs reflected high level of social conversation skills: questioning, taking turns, proposing, substantiating a proposition, suggesting and concluding.

\subsection{Effects and Impacts}

Access in maternal care services in Amhara show that since the introduction of the 1-5 cells and 1-30 health development army structures in one year significant results have been underscored in 2013 (see table 1 below).

Table 1. Health provider assisted birth in the study area

\begin{tabular}{lll}
\hline region/zone/disrtict & $\mathbf{2 0 1 2}$ & $\mathbf{2 0 1 3}$ \\
\hline Amhara region & $11 \%$ & $32 \%$ \\
West Gojam Zone & $11 \%$ & $30 \%$ \\
South Wollo Zone & $16 \%$ & $46.4 \%$ \\
Dembecha district & $18 \%$ & $48 \%$ \\
Quarit district & $11 \%$ & $51 \%$ \\
Leghida district & $10 \%$ & $37 \%$ \\
Albuko district & $11 \%$ & $48.8 \%$ \\
\hline
\end{tabular}

Source: regional, zonal and district health offices

All informants from region to district gave the credit to the 1-5 and 1-30 cells and health development armies, the health extension workers and the kebele leadership.

Socio cultural perceptions and practices of birth are frequently mentioned in maternal health care studies as major inhibiting factors for women in their decision making with regards to place of birth. The networks have enabled all stakeholders and players in maternal care to develop a shared understanding of the benefits of institutional maternal care including birth. All study participants exhibited behaviors of awareness of maternal care during pregnancy, birth and after birth and risks associated with pregnancy and birth.

Influential elders (men and women) mentioned of women and new born that died because of pregnancy and birth related complications associated with home birth. They reported of the deaths of mothers and newborn that used to happen in their old days. Elderly women reported of long labor that took days and deaths of mothers that happened because of bleeding and rapture. They also reported of the painful practices that traditional birth attendants did in an effort to save women with complicated birth which in most cases result in the death of mothers and newborn.

Husbands are major players in motivating women to give birth at health centers. Health providers reported that husbands bring their pregnant wives for antenatal care and birth to health facilities. They attend maternal education and counseling along their wives; this includes preparation for birth in health facilities.

During the field work, religious fathers were observed accompanying their wives for antenatal care and birth including family planning counseling. All were interviewed and said that they teach women to make use of maternal health care services including birth at health centers and also discuss such issues in their networks of 1-5 and kebele gatherings with health extension workers. A religious father in Quarit said that 'God has given man over three hundred domains of knowledge, and health care is one of them. What health providers do is what God has given to man.'

Giving birth at health facility has become the first choice of communities and women especially. Their major complaints are distance, unavailability of ambulance during emergency and limited skills and abilities of providers in health centers. Cost incurred with referrals is a frequently mentioned complaint. Although the government has made ambulance services and care received at health facility free of charge, other logistical costs related to dislocation from home remain a concern for poor families. Such families are supported by the networks; however they say it is not enough to cover all costs associated with dislocation. They said that through the networks they are negotiating with government to strengthen health posts and health centers so that they get maternal care services including CS at close distance. Health capacities with better services such as Dembecha health center, for example, provider assisted birth has increased from a monthly of 7 a year ago to 65 per month; and that of Quarit health center form monthly average of 3 to 25 in 2014. (Source: health facility document).

Availability of maternity waiting home in health centers and hospitals is important to avoid carrying women for a long distance during complications. Many women who have had experience of complications and those who wanted to avoid risks associated with home birth travel before one or two weeks of EDB (expected date of birth)to nearby health 
centers. They stay in waiting rooms; and if a maternity waiting home is available, they stay there till birth. Community informants demanded that maternity waiting homes should be conducive for pregnant women. They suggested that maternity waiting homes should be well resourced. Informants said communities could contribute financially or in kind to minimize the expenses that families incur because of longer time of dislocation from home. In Leghida district there is a monthly contribution of one Birr and a kilo of cereal per household that farmers give to cover maternal care expenses during emergency for any member. It is a kind of insurance.

The number of women receiving postpartum care has increased. It used to be a neglected area and in effect women and new born used to die as a result of infections associated with birth and lack of post partum care services. The Welega study [14] showed that even early post partum care looked to be given marginal attention at facilities. In Amhara post partum care has been enhanced since the HAD networks have been made operational. According to a West Gojam zonal health office report number of women receiving post partum care increased from $10 \%$ to $70 \%$ in 2013[15]. Ambulances are required to return women after birth to their homes. Health extension workers closely monitor such woman on regular basis for the first 15 days and intermittently for the subsequent one month. The visits made by health extension workers for post partum care are reported and evaluated by health centers. A health center monitors at least five health posts in five villages. The health extension workers report any abnormality in the mother and new born to health centers, advise mothers on breast feeding, managing the new born, sanitary and hygienic practices including routine vaccination.

Interviews and FGDs conducted with women in reproductive age, husbands, and influential elders (men and women), community and religious leaders demonstrated that the discourses they make in health are elaborated. They are well substantiated and informants have demonstrated knowledge why women should follow maternal care services: ANC, delivery at health facility and postpartum care. Home birth is associated with backwardness and exposing oneself to risks including death. Those who reported of home birth say that it happened because of transportation problems and the emergency nature of the labor. Almost all such women reported that they were taken to health facility after the birth for medical checkup.

Although there was expectation that the informants selected would demonstrate variations in their perceptions and attitude as well as assessment of maternal health care services, the discourses in maternal health care are getting depth irrespective of type of informant. Participants reflected high level of knowledge, positive attitude and desire to get quality services at close distance. Elderly women and men, in fact, were able to compare maternal care and delivery practices in their time against to what is happening now with the support of the government. They use their experiences to motivate their daughters to use health facility for maternal health care services. In Albuko district one of the complaints was lack of mobile network, and informants said that they could not call from their villages for ambulance service on seeing signs of labor. Keeping the call number of the ambulance unit is frequently mentioned by women, husbands and elders.

One of the effects of the networked approach is on mitigating teenage pregnancy. Underage marriage, abduction, rape and coerced sex are frequently mentioned in studies and health reports as contributing factors to teenage pregnancy and related complications in Ethiopia. All these practices are criminalized under the revised family law. It has not been easy to monitor and stop such practices, however. The HAD networks and substructures of 1-5 have made incidents associated with underage marriage, coerced sex and rape very rare happenings. This is done through cell conversations, and the ability of the structures to work closely with law enforcing bodies. Teenage pregnancy, nevertheless, is prevalent among school and college students in towns. It is very much associated with modernity which motivates teenagers to engage in sex, even for gift.

\subsection{Impacts}

The main impact of the networks is that communities have been empowered to take a lead in dealing with their health problems. All informants interviewed reported that they feel a sense of duty to assist a pregnant woman in order to give birth at health facility. The cells along with their health development armies have developed cohesiveness and unity of purpose. They are essentially a political force and are demanding more on health care delivery services in terms of availability and quality. In the discussions conducted with the various groups practically all speak the same language on maternal care and the services deliverable through the health system. The ecologically innovated social mobilization structures and networks have promoted community empowerment and ownership.

\section{Discussions and Recommendations}

The key question is what make(s) the HDA based network approach effective as a tool for social mobilization towards boosting maternal health care seeking behavior in communities?

\subsection{Discussions}

(i) Contextualization of health information and messages

The HAD approach to health promotion was able to create context based synergy of players and resources for change communication in health. The network of 1-5 and 1-30 has an ecological capacity to engage members in the making of health discourses by relating the health information and messages they get from health extension workers and health providers in health facilities to their way of life. The process generated better understanding of the issues and generates more questions to be resolved at cell, HAD, Kebele and 
district levels. The process also allows more input to be generated by beneficiaries and engage community health workers and health facility based providers in the process of learning and confidence building while mitigating heath problems. This situation has forced community health workers to deal with one package activity say maternal health care at a time. In effect this has transformed the health extension program from a sort of orientation to an educational program. The depths of knowledge the informants and FGD participants show indicate how the approach enhanced beneficiary understanding of modern health care services.

\section{(ii) Inclusiveness and accountability in health}

The approach is inclusive. Each team has to work through all possible means such as counseling, family discussion to bring members to the same level of understanding of health care. Cells are evaluated by their group performance, so also health development armies, kebeles and districts. The same is true with health service delivery by community health workers and health facility providers. The approach addresses accountability to health care at individual, team and institutional levels.

(iii) Confidence building and commitment to health care

The approach promotes reasoning, not mere conditioning. It empowers communities to deal with health risks, not through fear but through confidence building, for they learn how to prevent risks such as choosing a health facility for birth instead of home [3]. The approach requires both the beneficiaries and suppliers of health services to engage in dialogues such as the use of pregnancy women's conferences where facility service delivery is critiqued. The approach requires administrative officers, different wings of the ruling party such as youth, women, farmers' associations and nongovernmental partners to work together to educate communities to make use of available health services and as well contribute towards the improvement of service delivery. Overall, the approach helps communities to engage in the realization of their potential in development particularly in health care.

(iv) Governance and rules

The approach is not a laissez-faire thing. It is both structured and ecological. It is structured in that there is a hierarchy starting from cell leader to a command post. It is ecological in that it takes community values and norms as a way of working together to active a common goal say reduction of maternal and new born death. It prepares members to assume responsibility for the wellbeing of communities as social groups with common destinies. As members are empowered in health ownership, they are also required to work to better health of their communities by producing good health.

(v) Knowledge is in the community

Knowledge is embedded in nature and so also is in community. The process and thinking in the network creates favorable conditions to engage communities and providers in heath in a dialectical process of behavior change. On the basis of the discourses in health created by relating health information and messages to context, communities engage in the generation of questions and demands in health care services. They also engage in exploring ways to be part of the answers. They have demanded for quality care services at health facilities, they have also suggested how they could be part of the answer; they have demanded for access roads, they have also suggested they can be part of the labor force in the construction of rural roads. Each achievement leads to a question followed by a pursuit to find an answer; in doing so health development is realized. The remarkable progress being made in health is a testimony to this process.

\subsection{Recommendations}

To push the button of dialectical process of change the following recommendations are forwarded.

(i) At the community level

(a) The structures in place should be strengthened through training of cell and HAD leaders and community health workers. As facilitators of health communication and educational activities they need more training in agenda setting and turn distribution during group interaction and reporting.

(b) Engage communities in the building of access roads and also in contributing in health facility expansion activities such as maternity waiting homes and the like. Communities in the study suggested that they were ready to engage in such roles. It is not only raising demand in communities for health care, communities have to be boosted to be part of the supply side in health care services as well.

(ii) Improve health service delivery by engaging all stakeholders in health

(a) Improve response to emergency situations--the ambulance services have to be strengthened by putting more ambulances into operation, midwives at heath centers must be able to deliver BEmONC care services;

(b) Maternity waiting homes should be designed to meet the private needs of women. Distance is a problem and access by road will remain a problem, unless farmers settled in scattered sub villages are resettled in accessible areas. The best solution is to make maternity waiting homes available near facilities where at least $\mathrm{C} / \mathrm{BEmoNC}$ services available for such women;

(c) Build more district hospitals with facilities to deliver $\mathrm{C} / \mathrm{BEmoNC}$ services in accessible locations;

(d) Strengthen health posts to deal with emergency situations with vaginal birth and capability to control bleeding;

(e) Promote facility revenue generation through cost sharing of none critical heath care services; nevertheless, keep maternal, child care and management of epidemic infectious diseases free of charge. Ethiopia has made this scheme operational and in effect facilities have started generating funds which they are using for improving essential health care 
services.

(iii) Increase budget of the health sector

(a) Government budget in health is less than the expected budget requirement for health in countries like Ethiopia, for example. It should be raised as per WHO recommendations.

(b) Gear international aid in health towards strengthening facility based services such as training of health providers, strengthening key components of health systems-logistics, equipment, facility space.

\section{Acknowledgment}

The author acknowledges Dr. Aklilu Kidanu, director of Miz-HasabResearch Center , Drs Wessel Wijkman and FrankVan Doren of Mango Consult; Dr Yetnayet Demisse Asfaw, Ato Jemal kassaw and Ellen Brazier of EngenderHealth Ethiopia, for supporting the study on Boosting Maternal Care Seeking Behavior in Welega and Amhara through the funds obtained from the Dutch Government -ORIO Program . The author, the PI of the two studies, used the data to write the paper. The contribution of Negasi Abay, Adeko Wolde and Seyoum Abraham in assisting the author during data collection in Amhara is duly acknowledged, too.

\section{Appendix}

Table 2. Health leaders: key informants

\begin{tabular}{ll}
\hline Type of key informant & Total \\
\hline $\begin{array}{l}\text { Wereda informants: health, education, Women -children-youth, } \\
\text { and Communication offices - heads/representatives }\end{array}$ & 16 \\
$\begin{array}{l}\text { Zonal informants-- health, education, Women -children-youth, } \\
\text { and Communication offices - heads/representatives }\end{array}$ & 8 \\
$\begin{array}{l}\text { Regional deputy bureau head, maternal and child expert and } \\
\text { health promotion and disease prevention }\end{array}$ & 3 \\
Total & 27 \\
\hline
\end{tabular}

At zonal and district levels development activities are integrated. In order to get the perspectives of key players in health, health and other related sector officers in education, women, children and youth affairs and government communication were included; one informant from each office at district and zone levels: 16 for districts and 8 for zones. At regional level, informants were purposely selected to represent the views of the regional health bureau: the bureau deputy bureau head in charge of maternal and child health, two senior experts in maternal and child health and health promotion and disease prevention, one from each department, in total 3 (see table 2).

Table 3. Number and type of kebele participants and nearby HC staff

\begin{tabular}{|c|c|c|c|c|c|}
\hline Type of participant & $\begin{array}{l}\text { West Gojjam: } \\
\text { Quarit-- Village 1 } \\
\end{array}$ & $\begin{array}{l}\text { West Gojjam: } \\
\text { Dembecha: Village } 2\end{array}$ & $\begin{array}{l}\text { South Wollo: } \\
\text { Leghida Village } 3 \\
\end{array}$ & $\begin{array}{l}\text { South Wollo: } \\
\text { Alebuko Village } 4 \\
\end{array}$ & Total \\
\hline $\begin{array}{l}\text { Adolescent women (15-24) with recent } \\
\text { births }\end{array}$ & 3 & 4 & 3 & 3 & 13 \\
\hline $\begin{array}{l}\text { Mature married women (20-49) with } \\
\text { recent births }\end{array}$ & 3 & 3 & 4 & 4 & 14 \\
\hline *Married men & 3 & 3 & 4 & 3 & 13 \\
\hline $\begin{array}{l}\text { **Woman with birth complication in last } \\
\text { six months }\end{array}$ & 2 & 1 & - & 1 & 4 \\
\hline Influential elderly women & 2 & 2 & 2 & 2 & 8 \\
\hline Influential elderly men & 2 & 2 & 2 & 2 & 8 \\
\hline Community leaders & 4 & 3 & 4 & 4 & 15 \\
\hline Religious leaders & 2 & 1 & 2 & 2 & 7 \\
\hline $\begin{array}{l}\text { Health extension workers/ health dev. } \\
\text { Army members }\end{array}$ & 1 & (FGD) & 1 & 1 & 3 \\
\hline Facility Based health care providers & 6 & 4 & 6 & 5 & 21 \\
\hline Total & 28 & 23 & 28 & 27 & 106 \\
\hline
\end{tabular}

The community informants were selected by design. Adolescent women in the age range of 15-24 were selected to capture experiences of young women in maternal care particularly birth; 13 young women participated in the study. Mature women in the age range of 25-49 with recent births were included to capture their perspectives of maternal care especially assisted birth, both traditional and institutional care: 14 women participated. Husbands were included because they play important role in decision making with regards to maternal care. It was necessary to get their thinking of institutional birth as compared with cultural and traditional practices; especially those factors that influence husbands' decision making with regards to women accessing health facility based maternal care-- 13 husbands participated. Women with birth complication in last six months were included in order to capture their experiences of complications and how they were assisted in health facilities. It was felt that their experiences matter if women are to seek care services in health facilities--4 women participated. Influential elderly women were included because they have had experiences in pregnancy and birth managed according to traditional practices and beliefs. They influence young women on the bases of their experiences as to whether to seek institutional care or not; 8 participated. Influential elderly men, community and religious leaders were included because they act as community guardians and their opinions matter a lot; they can act as catalysts to boost or deter institutional maternal care: 8,15 and 7 participated respectively. Community and health facility informants were included to give their views on community health seeking 
behavior, service delivery at facilities, processes and changes observed in community maternal health care seeking behavior, as well as barriers and obstacles towards maternal care at communities and health facilities.( see table 3 below).

The FGD participants were selected by design as well as on availability during data collection. They included women in reproductive age (young and older), influential women, husbands and community health workers. The FGDs were conducted to synthesize ideas as to what motivate and as well inhibit young women to make use of institutional maternal care services; how older women in reproductive age view institutional health care when compared to their earlier experiences of traditional care during pregnancy, home birth and post birth; reflect on advantages and disadvantages and what could be done to make institutional maternal care inclusive of the advantages women see in delivering at home. Influential women and husbands were included to reflect on their common experiences and decision making processes with regards to preparation for birth, selection of place of birth and post natal care. Community health workers were included as FGD participants because they link the community with health facilities. Their experiences of the boosters and inhibitors for women to access institutional maternal care are important for the study. (see table 4).

Table 4. Community FGDs

\begin{tabular}{|c|c|c|c|c|c|}
\hline Type of participant & $\begin{array}{l}\text { West Gojjam: } \\
\text { Quarit-- Village 1 } \\
\end{array}$ & $\begin{array}{l}\text { West Gojjam: } \\
\text { Dembecha: Village } 2\end{array}$ & $\begin{array}{l}\text { South Wollo: } \\
\text { Leghida Village } 3 \\
\end{array}$ & $\begin{array}{l}\text { South Wollo: } \\
\text { Alebuko Village } 4 \\
\end{array}$ & Total \\
\hline Women of reproductive age $15-24$ & 1 & 1 & 1 & 1 & 4 \\
\hline Women of reproductive age $-25-49$ & 1 & _- & 1 & 1 & 3 \\
\hline Influential women & - & - & 1 & - & 1 \\
\hline Husbands & 1 & 1 & 1 & 1 & 4 \\
\hline $\begin{array}{l}\text { *Health extension workers/ health } \\
\text { dev. Army members }\end{array}$ & 1 & 1 & - & - & 2 \\
\hline
\end{tabular}

*The women of reproductive age are also leders of 1-5 cells and help extension workers.

\section{References}

[1] Abebaw Gebeyehu Worku, Alemayehu Worku Yalew and Mesganaw Fantahun Afework(2013) Factors affecting utilization of skilled maternal care in Northwest Ethiopia: a multilevel analysis. BMC International Health and Human Rights 2013, 13:20 http://www.biomedcentral.com/1472$698 \mathrm{X} / 13 / 20$

[2] Banteyerga, Hailom. 2011. Ethiopia's health extension program: improving health through community involvement. MEDICC

rev. vol.13 no.3 Oakland Jul. 2011.(PERESPECTIVE) http://dx.doi.org/10.1590/S1555-79602011000300011

[3] Baranowski,T., Perry,C.L. \& Percel,G.S. (2002). How individuals, environment and health behavior interact. In Glaz, K. Lewis, F.M., Rimer, B. (eds): Theory research \& practice. San Francisco, Josey-bass: 155-178

[4] Bedford, Juliet, Meena Gandhi, Metasebia Admassu ,Anteneh Girma (2012) 'A Normal Delivery Takes Place at Home': A Qualitative Study of the Location of Childbirth in Rural Ethiopia. Maternal Child Health J DOI 10.1007/s10995-0120965-3

[5] Chaya, Nada. (2007)Poor Access to Health services: Ways Ethiopia is Overcoming. Population Action International. Volume 2 issue 2. www.populationaction.org

[6] CSA (2011).Ethiopia Demographic and Health Survey (EDHS) 2011. Central Statistical Agency, Addis Ababa, Ethiopia. ICT International, Calverton MD, USA. 2012

[7] Family Care International - Skilled Care Initiative Qualitative Research www.familycareintl.org/en/issues/29
[8] Federal Ministry of Health (1997). Health Sector Development Program, I. FMOH, Addis Ababa

[9] Federal Ministry of Health (2003). Health Extension Program, I. FMOH, Addis Ababa

[10] Federal Ministry of Health (2011). Health Sector Development Program, IV. FMOH, Addis Ababa.

[11] Federal Ministry of Health (2014). Health Sector Development IV Annual performance Report. ARM 16-Doc $02 / 14$. Version 1.

[12] Federal Ministry of Health (2014). Special Bulletin $16^{\text {th }}$ Annual Review meeting, 2014. ARM 16-Doc 04/14.[World Statistics, 2014, WHO]

[13] The Guardian. (nd)Ethiopia: too many deaths in childbirth as women opt out of healthcare. www.guardian.co.uk

[14] MHRC. 2013. Hailom Banteyrga (PI). Boosting Maternal and Child Health Care seeking Behavior Wollega, Oromia, Ethiopia, mimeographed.

[15] MHRC. 2014. Hailom Banteyrga (PI). Boosting Maternal and Child Health care seeking behavior: West Gojam and South Wello Zones of Amhara Region, Ethiopia, mimeographed.

[16] Rodgers, E.M. (1995). Diffusion of Innovations (fourth edition). New York: Free press.

[17] Transitional Government of Ethiopia (1993). The Health Policy. TGE: Addis Ababa.

[18] UNFPA (2013). Trends in Maternal Health in Ethiopia. http://www.unfpa.org/public/home/mothers/MMEstimates201 2/ www.itacaddis.org/.../2013_09_24_09_12_46_UNFPA\%20DH S\%20In-... 